\title{
ACTIVIDAD ANTIOXIDANTE DE PIGMENTOS ANTOCIÁNICOS ${ }^{1}$
}

\author{
E. Marta KUSKOSKI ${ }^{2,3}$, Agustín G. ASUERO ${ }^{3}$, M. Carmen GARCÍA-PARILLA ${ }^{3}$,
}

\author{
Ana M. TRONCOSO ${ }^{3}$, Roseane $\mathrm{FETT}^{2, *}$
}

\begin{abstract}
RESUMEN
Los antocianos son colorantes naturales pertenecientes al grupo de los flavonoides. Están presentes en casi todas las plantas y en todas sus partes, sobretodo en flores y frutos (particularmente en bayas). Para determinar la actividad antioxidante de los pigmentos antociánicos se ha utilizado el radical ABTS ${ }^{\bullet+}$ formado tras la reacción de 2,2 2`azinobis-(3-etilbenzotiazolin 6-ácido sulfónico) (ABTS) con persulfato potásico, incubados a temperatura ambiente y durante 16 horas. Se determinó la capacidad antioxidante de cinco antocianos puros: delfinidina, cianidina, peonidina, pelargonidina y malvidina todos ellos glucosilados en el C-3 del anillo C con excepción de la delfinidina. De los antocianos ensayados, delfinidina y cianidina 3-glucósido presentan mayor actividad antioxidante, 2 veces mas que el Trolox (antioxidante sintético de referencia). Los demás antocianos tienen menor actividad pero potencial equiparable al Trolox. Por lo tanto, además de las características colorantes, los antocianos poseen potente propiedad antioxidante.

Palabras-claves: antocianos; capacidad antioxidante; radical $\mathrm{ABTS}^{\circ}$.
\end{abstract}

\section{RESUMO}

ATIVIDADE ANTIOXIDANTE DE PIGMENTOS ANTOCIÂNICOS. As antocianinas são pigmentos naturais que pertencem ao grupo de flavonóides. Estão presentes em quase todas as plantas e em todas as partes, principalmente nas flores e frutos (particularmente nas bagas). Para determinar atividade antioxidante dos pigmentos antociânicos utilizou-se o radical ABTS ${ }^{\circ+}$ formado pela reação de 2,2 azinobis-(3-etilbenzotiazolin 6-ácido sulfónico) (ABTS) com persulfato de potássio, a temperatura ambiente por 16 horas. Determinou-se a capacidade antioxidante de cinco antocianinas: delfinidina, cianidina, peonidina, pelargonidina e malvidina todas glicosiladas no C-3 do anel C com exceção da delfinidina. Das antocianinas determinadas a delfinidina e cianidina 3-glicosideo apresentaram maior atividade antioxidante, duas vezes superior ao Trolox (antioxidante sintético padrão). As demais antocianinas tem menor atividade, porem com potencial equiparável ao Trolox. Portanto, além das características como pigmentos, as antocianinas possuem potente propriedade antioxidante.

Palavras-chave: antocianinas; capacidade antioxidante; radical $\mathrm{ABTS}^{\bullet+}$.

\section{1 - INTRODUCCIÓN}

Estudios realizados con compuestos polifenólicos y especialmente los flavonóides demuestran su capacidad antioxidante y su significativa contribución en la dieta, así como su efecto en la prevención de diversas enfermedades tales como: enfermedades cardiovasculares, cancerígenas y enfermedades neurológicas $[5,6,9,14,15,16,18]$.

Los polifenoles son efectivos donadores de hidrógenos, particularmente los flavonoides. Su potencial antioxidante es dependiente del número y de la posición de los grupos hidroxilos y su conjugación, así como de la presencia de electrones donadores en el anillo estructural [8], debido a la capacidad que posee el grupo aromático de soportar el desapareamiento de electrones por desplazamiento del sistema de electrones- $\pi$ [10].

Los antocianos, pigmentos flavonólicos, tienen una estructura química adecuada para actuar como antioxidantes, pueden donar hidrógenos $[8,20]$, o electrones a

\footnotetext{
1. Recebido para publicação em 08/02/2004. Aceito para publicação em 09/11/2004 (001293).

2. Departamento de Análisis Químico y Departamento de Bioquímica, Bromatología y Toxicología, Facultad de Farmacia, Universidad de Sevilla, C/ García González s/n, 41012 - Sevilla, ES.

3. Departamento de Ciência e Tecnologia de Alimentos, Centro de Ciências Agrárias, Universidade Federal de Santa Catarina. Rod. Admar Gonzaga 1346, CEP: 88034-001. Itacorubi, Florianópolis.

* A quem a correspondência deve ser enviada.
}

los radicales libres o bien atraparlos y desplazados en su estructura aromática [10]. Una actividad antioxidante óptima se relaciona con la presencia de grupos hidroxilos en las posiciones $3^{\prime}$ y $4^{\prime}$ del anillo B, los cuales confieren una elevada estabilidad al radical formado [5, 14]. Los grupos hidroxilos libres en las posición 3 del anillo $\mathrm{C}$ y en la posición 5 del anillo A, junto con el grupo carbonilo en la posición 4 son donadores de electrones [12]. La diversidad estructural contribuye favorablemente a la existencia natural de unos 300 antocianos con diferentes sustituciones glucosídicas [5], en la estructura básica del ion fenil-2-benzopirilio o flavilio, representado en la Figura 1 los principales antocianos.

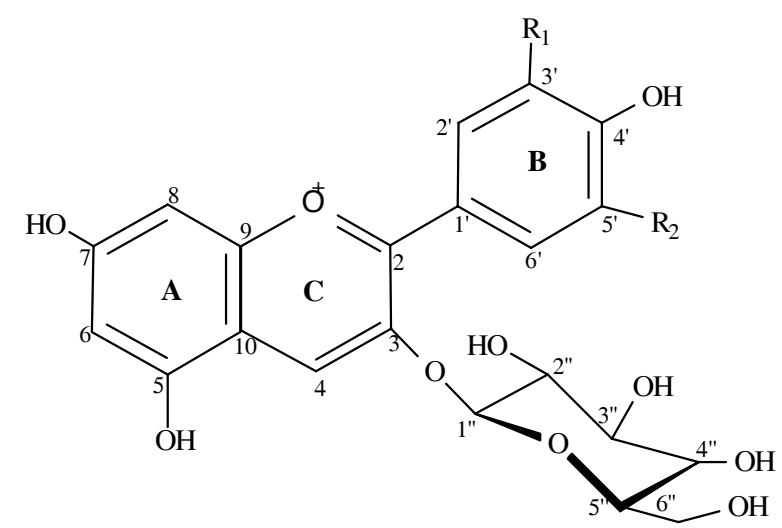

FIGURA 1. Estructura química de los antocianos. Dp (1, $\left.\mathrm{R}_{1}=\mathrm{OH}, \mathrm{R}_{2}=\mathrm{OH}\right) ; \mathrm{Cy} 3$-glu $\left(3, \mathrm{R}_{1}=\mathrm{OH}, \mathrm{R}_{2}=\mathrm{H}\right)$; Pg 3-glu (5, $\left.\mathrm{R}_{1}=\mathrm{H}, \mathrm{R}_{2}=\mathrm{H}\right)$; Pn 3-glu (6, $\left.\mathrm{R}_{1}=\mathrm{OCH}_{3}, \mathrm{R}_{2}=\mathrm{H}\right)$; Mv 3-glu (7, $\mathrm{R}_{1}=\mathrm{OCH}_{3}, \mathrm{R}_{2}=\mathrm{OCH}_{3}$ ). 
Actualmente el método ABTS tiene sido ampliamente usado tanto para materiales biológicos, compuestos puros o extractos de plantas de naturaleza hidrófila o lipofilica. El compuesto cromógeno ABTS presenta color azul/verde con máximo de absorción a 342nm, es muy soluble en agua y químicamente estable [1]. El radical ABTS $^{\bullet+}$ una vez generado por medio de enzimas (peroxidasa, mioglobina) [7] o químicamente (dióxido de manganeso, persulfato potásico o ABAP [2,2-azobis-(2amidinopropeno) $\mathrm{HCl}]$ [11, 17, 19], pasa a presentar nuevas características con máximos de absorción a 414, 645,734 y $815 \mathrm{~nm}[7,13]$.

El radical $\mathrm{ABTS}^{\bullet+}$ es mas indicado para ensayos de compuestos coloreados, como el caso de los antocianos, por presentar absorción máxima próxima a la región infrarroja $(734 \mathrm{~nm})$ reduciendo posibilidades de interferencias de compuestos coloreados que absorben en la región del visible o compuestos resultantes de reacción secundaria. Además radical generado químicamente (persulfato potásico) desarrollado por RE et al. [11], fue validado por su estabilidad, reproducibilidad y por ser una alternativa mucho más viable económicamente al método anteriormente descrito [7]. El objeto de este estudio fue determinar y comparar la actividad antioxidante de distintos antocianos 3-o-glucosilados, aplicando el método ABTS [1 1] observando la longitud de onda específica para estos compuestos.

\section{2 - MATERIAL Y MÉTODOS}

\section{1 - Material}

Se utilizó Trolox (6-hidroxi-2,5,7,8-tetrametilcromo2-ácido carboxílico 97\%, Aldrich Chemical Co., Gillingham, Dorset, UK) como antioxidante de referencia. Los antocianos peonidina 3-glucósido (Pn 3-glu), pelargonidina 3-glucósido (Pg 3-glu); malvidina 3-glucósido (Mv 3-glu); delfinidina (Dp) y cianidina 3-glucósido (Cy 3-glu) se obtuvieran de Extrasynthèse (Lyon-Nord, Francia). El ABTS, 2,2`azinobis (3-etilbenzotiazolin 6-ácido sulfónico) en forma de sal diamónica y el persulfato potásico (ultrapuro) fueran obtenidos de Sigma Aldrich (Poole, Dorset, UK). Los antocianos fueron disueltos en etanol acidificado a pH 1,3 a una concentración de 0.5mM. Todos los ensayos se efectuaran en un Espectrofotómetro modelo HP 8452A (Cheadle Heath, Stockport Cheshire, UK) con celula de temperatura controlada.

\section{2 - Actividad antioxidante}

Con modificaciones en la metodología desarrollada por $\mathrm{RE}$ et al., [11] el radical $\mathrm{ABTS}^{\circ+}$ se formó tras la reacción de ABTS $(7 \mathrm{mM})$ con persulfato potásico $(2,45 \mathrm{mM}$, concentración final) incubados a temperatura ambiente y en oscuridad durante $16 \mathrm{~h}$. Una vez formado el radical ABTS $^{\circ+}$ se diluyó con etanol hasta obtener un valor de absorbancia de 0,700 $\pm 0,100$ a $754 \mathrm{~nm}$ (longitud de máxima absorción). Las muestras filtradas (antocianos) se diluyeron con etanol hasta que se obtuvo un $20-80 \%$ de inhibición comparadas con la absorbancia del blanco tras añadir $20 \mu \mathrm{L}$ de la muestra. A $980 \mu \mathrm{L}$ de dilución del radical $\mathrm{ABTS}^{\circ+}$ así generado se le determina la $\mathrm{A}_{754}$ a $30^{\circ} \mathrm{C}$, se añade $20 \mu \mathrm{L}$ de la muestra (dilución de antocianos) y se mide de nuevo a $\mathrm{A}_{754}$ pasado 1 minuto. La absorbancia fue continuadamente medida después de 4 minutos. El antioxidante sintético Trolox

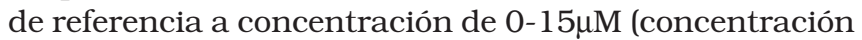
final) en etanol se ensayó en las mismas condiciones y los resultados son expresados en TEAC (actividad antioxidante equivalente a Trolox).

\section{3 - RESULTADOS Y DISCUSIÓN}

Los máximos de absorción del radical ABTS ${ }^{\bullet+}$ generado por persulfato potásico disuelto en etanol se observan claramente en Figura 2, que no coincide los máximos de absorción de los antocianos. Una vez que la solubilidad y estabilidad del radical $\mathrm{ABTS}^{\bullet+}$ depende de la reacción por la cual es generado y del medio en que esté disuelto, presentando así este radical tres puntos máximos de absorción 414, 752 y 842nm en medio acuoso y 414, 730 y 873 en medio etanólico generado enzimáticamente [2], y $753 \mathrm{~nm}$ en medio acuoso cuando se genera por adición de ABAP [2,2-azo-bis-(2-amidinopropano) HCl] [19]. Se eligió entonces como longitud de onda para efectuar las medidas, el segundo máximo $(\lambda=754 \mathrm{~nm})$, pues a partir de $650 \mathrm{~nm}$ la absorbancia de la muestra resulta ser nula. La estabilidad del radical formado se comprobó mediante medidas de la absorbancia a $754 \mathrm{~nm}$ a intervalos de 6 horas, y se pudo comprobar cómo el radical se mantiene estable por un período superior a 24 horas una vez transcurridas las primeras 18 horas iniciales desde su generación. La disolución del radical puede ser utilizada hasta pasadas 48 horas después de haberse generado.

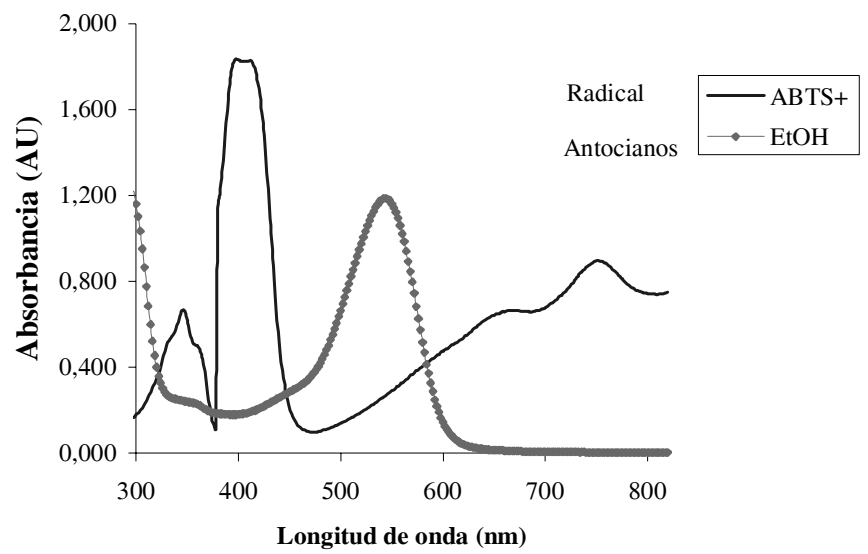

FIGURA 2. Superposición de los espectros del radical ABTS*+ $\mathrm{y}$ antocianos disueltos en etanol.

Los resultados obtenidos aplicando el método ABTS nos llevan a la conclusión de que aquellas agluconas con idéntica hidroxilación en los anillos A y C, y compuestos con solo un grupo $\mathrm{OH}$ en el anillo $\mathrm{B}\left(4^{\circ}-\mathrm{OH}\right)$ incluyendo pelargonidina, malvidina y peonidina presentan menor actividad antioxidante comparado con compuestos que poseen agrupación $3^{-}, 4^{-}$di-OH 
sustituidos como delfinidina y cianidina 3-glucósido (Tabla 1). La importancia de los grupos hidroxilos en la posición $3^{`}$ y $4^{\prime}$ del anillo B contribuye a la elevada capacidad antioxidante también encontrada en las flavonas $[3,12,14,20]$.

TABLA 1. Determinación del TEAC (actividad antioxidante equivalente a Trolox) de patrones de antocianos por método ABTS (media $\pm \mathrm{DE}, n=3$ ).

\begin{tabular}{ccc}
\hline Antocianos & Denominación & TEAC $(\mathrm{mM})$ \\
\hline Delfinidina & cloruro de delfinidina & $2,45 \pm 0,14$ \\
Cianidina 3-glucósido & cloruro de kuromanin & $1,85 \pm 0,26$ \\
Peonidina 3-glucósido & cloruro de peonidina 3-glucósido & $1,49 \pm 0,19$ \\
Pelargonidina 3-glucósido & cloruro de callistephin & $1,50 \pm 0,08$ \\
Malvidina 3-glucósido & cloruro de oenin & $1,41 \pm 0,07$ \\
\hline
\end{tabular}

Por otra parte los flavonoides con un mayor numero de grupos hidroxilos tienen mayor actividad antioxidante [4]. Como se comprueba para los antocianos con grupos hidroxilos en las posiciones 4,5 y 6 , que presentan valores de actividad antioxidante de 1,50; 1,85; y 2,45 (media $\pm \mathrm{DE}, n=3$ ) (Tabla 1) como pelargonidina, cianidina y delfinidina respectivamente. Así como la eficacia de los flavonóides como antioxidantes esta relacionada con el grado de hidroxilación, también desciende con la sustitución por azúcares, presentando los glucósidos menor actividad antioxidante que sus correspondientes agluconas [20].

\section{4 - CONCLUSIÓN}

Los compuestos antociánicos ensayados presentan actividad antioxidante equiparable o mayor que Trolox, de acuerdo con la diferente sustitución hidroxil o metoxilo. Entre los antocianos ensayados con el método ABTS en longitud de onda a $754 \mathrm{~nm}$, delfinidina y cianidina 3-glucósido presentarán actividad antioxidante cerca de dos veces superior al Trolox. El resto de antocianos tienen menor actividad pero con potencial equiparable al Trolox. Por lo tanto, además de las características colorantes, los antocianos poseen potente propiedad antioxidante.

\section{5 - REFERENCIAS BIBLIOGRAFICAS}

[1] ANTOLOVICH, M.; PRENZLER, P.D.; PATSALIDES, E.; MCDONALD, S.; ROBARDS, K. Methods for testing antioxidant activity. Analyst, v. 127, p. 183-198, 2002.

[2] ARNAO, M.B. Some methodological problems in the determination of antioxidant activity using chromogen radicals: a pratical case. Trends in Food Science \& Technology. v. 11, p. 419-421, 2000.

[3] BORS, W.; HELLER, W.; MICHEL, C.; SARAN, M. Flavonoids as antioxidants; determination of radicalscavenging efficiencies. Methodos Enzymol.v. 186, p. 343-355, 1990.

[4] CAO, G.; SOFIC, E.; PRIOR R.L. Antioxidant and prooxidant behavior of flavonoids: Struture-activity relations ships. Free Rad. Biol. Med. v. 22, n. 5 , p. 749-760. 1997.
[5] HARBORNE, J.B.; WILLIAMS, C.A. Advances in flavonoid research since 1992. Phytochemistry. v. 52, p. 481-504, 2000.

[6] LAPIDOT, T.; HAREL, S.; AKIRI, B.; GRANIT, R.; KANNER, J. pH-Dependent forms of red wine anthocyanins as antioxidantes. J. Agric. Food Chem. v. 47, p. 67-70, 1999.

[7] MILLER, N.J.; RICE-EVANS, C.A. Factores influencing the antioxidant activity determined by the ABTS radical cation assay. Free Radical Research, v. 26, p. 195-199, 1997.

[8] MILlER, N.J.; RICE-EVANS, C.A. The relative contributions of ascorbic acid and phenolic antioxidants to the total antioxidant activity of orange and apple fruit juices and blackcurrant drink. Food Chem. v. 60, p. 331-337, 1997.

[9] PRIOR, R.L.; CAO, G.; MARTIN, A.; SOFIC, E.; MCEWAN, J.; O`BRIEN, C.; LISCHNER, N.; EHLENFELDT, M.; KALT, W.; KREWER, G.; MAINLAND, C.M. Antioxidant capacity as influenced by total phenolic and anthocyanin content, maturity and variety of Vaccinium specie. J. Agric. Food Chem. v. 46, p. 2686-2693, 1998.

[10] RAMIREZ-TORTOSA, C.; ANDERSEN, O.M.; GARDNER, P.T.; MORRICE, P.C.; WOOD, S.G.; DUTHIE, S.J.; COLlins, A.R.; DUTHIE, G.G. Anthocyanin-rich extract decreases indices of lipid peroxidation and DNA damage in vitamin $\mathrm{E}$ depleted rats. Free Rad. Biol. Med. v. 31, n. 9, p. 1033-1037, 2001.

[11] RE, R.; PELlegRINI, N.; PROTEGGENTE, A.; PANNALA, A.; YANG, M.; RICE-EVANS, C. Antioxidant activity applying an improved ABTS radical cation decolorization assay. Free Rad. Biol. Med. v. 26, p. 1231-1237, 1999.

[12] RICE-EVANS, C.A.; MILleR, N.J.; PAPAGANDA, G. Structure antioxidant activity relationships of flavonoids and phenolic acids. Free Rad. Biol. Med. v. 20, p. 933-956, 1996.

[13] ROBARDS, K; PRENZLER, P.D.; TUCKER, G.; SWATSITANG, P.; GLOVER, W. (1999). Phenolic compunds and their role in oxidative processes in fruits. Food Chem. v. 66, p. 401-436.

[14] SÁNCHEZ-MORENO, C. Compuestos polifenólicos: efectos fisiológicos. Actividad antioxidante. Alimentaría. ene-feb, p. 29-40, 2002.

[15] SAUTÉ-GRACIA, M.T.; HEINONEN, M.; FRANKEL, E.N. Anthocyanin as antioxidants on human low-density lipoprotein and lecithin-liposome systems. J. Agric. Food Chem. v. 45, p. 3362-3367, 1997.

[16] SCHRAMM, D.D.; GERMAN, J.B. Potential effects of flavonoids on the etiology of vascular disease. J. Nutr. Biochem. v. 9, p. 560-566, 1998.

[17] SEllapPan, S.; AKOH, C.C.; KREWER, G. Phenolic compounds and antioxidant capacity of Georgia-Grown blueberries and blackberries. J. Agric. Food Chem. v. 50, p. 2432-2438, 2002.

[18] TSUDA, T.; WATANABE, M.; OHSHIMA, K.; NORINOBU, S.; CHOI, S.W.; KAWAKISHI, S.; OSAWA, T. Antioxidative activity of the anthocyanin pigments cyanindin 3-O-b-D glucoside and cyanidin. J. Agric. Food Chem. v. 42, p. 2407-2410, 1994.

[19] VAN DEN BERG, R.; HAENEN, G.R.M.M.; VAN DEN BERG, H.; BAST, A. Applicability of an improved trolox equivalent antioxidant capacity (TEAC) assay for evaluation of antioxidant capacity measurements of mixtures. Food Chem. v. 66, p. 511-517, 1999.

[20] WANG, H.; CAO, G.; PRIOR, R. Oxygen radical absorbing capacity of anthocyanins. J. Agric. Food Chem. v. 45, p. 304-309, 1997. 